\title{
Numerical prediction of the ductile damage for axial cracks in pipe under internal pressure
}

\author{
Fezazi Amina Ismahène, Mechab Belaï, Salem Mokadem, Serier Boualem \\ University of Djillali Liabes, LPMM Laboratory, SidiBel Abbes, Algeria \\ fezaziismahane223@gmail.com,bmechab@yahoo.fr,moka_salem@yahoo.fr,boualems@yahoo.fr
}

\begin{abstract}
This study presents a numerical prediction of the ductile damage for axial cracks in pipe subjected to internal pressure. The three dimensional finite element methods used to evaluate the J-integral. The effect of the external radius $\left(\mathrm{R}_{\text {ext }}\right)$, thickness of the pipe $(\mathrm{t})$, length crack (a), applied loads (P) and crack position has studied. The Monte Carlo method was used to determine the probabilistic characteristics of the J-integral. It's also used later to predict the failure probability based on initiation of the crack growth. We note that the crack size and the geometries of the pipe are an important factor influencing on the durability of the pipe.
\end{abstract}

KEYWORDS. Failure; Pipe; Fracture mechanics; Monte Carlo method.

\section{OPEN $\bigcirc$ ACCESS}

Citation: Fezazi, A. I., Mechab, B., Salem, M., Serier, B., Numerical prediction of the ductile damage for axial cracks in pipe under internal pressure, Frattura ed Integrità Strutturale, 58 (2021) 231-241.

Received: 19.05 .2021

Accepted: 26.07.2021

Published: 01.10.2021

Copyright: (C) 2021 This is an open access article under the terms of the CC-BY 4.0, which permits unrestricted use, distribution, and reproduction in any medium, provided the original author and source are credited.

\section{INTRODUCTION}

$\mathrm{P}$ ipelines have been built to transport many other fluids (liquids and gases). For instance, liquid fertilizers are often transported long distances via pipelines. The mixture of oil and natural gas coming out of a well must be transported as two-phase flow by pipelines to processing facilities before the oil can be separated from the gas.

The fracture prediction and the reliability of such piping systems in various practical applications are primordial given their impact on the economic plan and security [1-4]. Several authors have been studied pipe fracture problems by means of numerical simulation in order to assess the mechanical integrity, taking into account different crack shapes [5-7].

The ductile fracture mechanics parameters for the cracked pipes subjected to internal pressure is important in structural integrity assessment of defective components [8-10]. The safety assessment of these structures and the comprehension of failure mechanisms are essential to study the reliability of pipelines for the liquid or gas transport [11-14].

Probabilistic fracture mechanics is a means of quantifying the failure probability resulting from uncertainties in the values of the parameters used to perform a failure assessment of cracked structures through probabilistic analysis techniques [1517]. Rahman [18] analyzed small cracks in tubes under internal pressure and bending loads, where one of the observations was that for through-wall-thickness cracks the effect of internal pressure was significant for high- 
hardening pipe materials, and insignificant otherwise. This study provides engineering J estimation for the ductile fracture mechanics of cracked pipe subjected to internal pressure. The effect of the of the external radius ( $R_{\text {ext }}$ ), thickness of the pipe $(\mathrm{t})$, length crack (a), applied loads $(\mathrm{P})$ and crack position has been studied by the three dimensional finite element method for evaluating the J-integral. The Monte Carlo method is used to predict the distribution function of the mechanical response of the structure.

\section{GEOMETRICAL MODELS}

7 his study presents a three-dimensional finite element analysis of the code ABAQUS [19] for the cracked pipes under internal pressure load. The crack length (a)ranged from $10 \mathrm{~mm}$ to $100 \mathrm{~mm}$, and the external radius $\left(\mathrm{R}_{\text {ext }}\right)$ varied from $250 \mathrm{~mm}$ to $800 \mathrm{~mm}$, the thickness of the pipe's (t) varied from $10 \mathrm{~mm}$ to $30 \mathrm{~mm}$ and the internal pressure $(\mathrm{P})$ varied from 10bar to 120bar (see Fig.1).
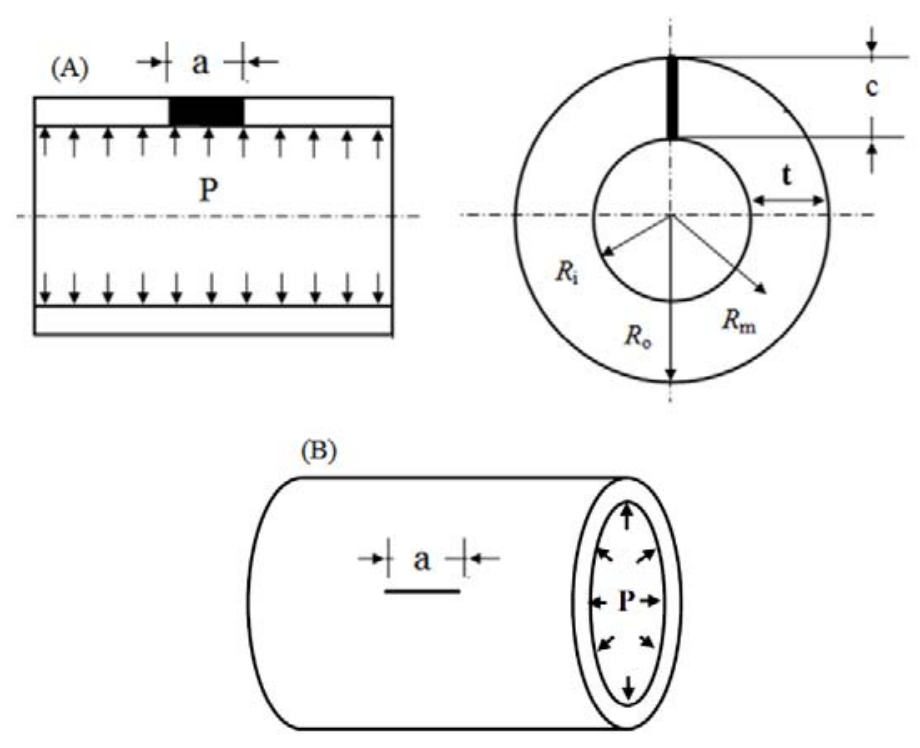

Figure 1: (a)definition of the longitudinal crack, (b) Schematic illustration for cracked pipes under internal pressure

\section{MATERIAL MODEL}

$\mathrm{F}$

E analyses were performed to calculate elastic-plastic fracture mechanics parameters. The material in the FE analyses is assumed to follow the Ramberg-Osgood (R-O) relation:

$$
\frac{\varepsilon}{\varepsilon_{0}}=\frac{\sigma}{\sigma_{y}}+\alpha\left(\frac{\sigma}{\sigma_{y}}\right)^{n}
$$

Tab. 1 give the mechanical properties of the material used in this study.

\begin{tabular}{cccccc}
\hline $\mathrm{E}(\mathrm{GPa})$ & $\sigma_{\mathrm{y}}(\mathrm{MPa})$ & $\sigma_{u}(\mathrm{MPa})$ & $v$ & $\alpha$ & $\mathrm{n}$ \\
203 & 302 & 450 & 0.3 & 18.826 & 3.887 \\
\hline
\end{tabular}

Table 1: Summary of tensile properties of SA333 Gr. 6 carbon steel [20]. 


\section{FINITE ELEMENT MESH}

$\mathrm{F}$ ig. 2 gives a typical FE mesh of the cracked pipe. An 8-node doubly curved thick shell, reduced integration (SD8R in ABAQUS) was used to analyses a model of the pipe. The $\mathrm{J}$ integral values were extracted using a domain integral method within ABAQUS. This method provides high accuracy with rather coarse models in threedimensions. The $\mathrm{J}$ integral values were extracted using a domain integral method within ABAQUS. This method provides high accuracy with rather coarse models in three-dimensions. The resulting finite element model as shown in Fig. 2. The crack tip was modelled with focused elements composed with 5 contours. The number of nodes and elements in the models studied are presented in Tab. 2 and 3.

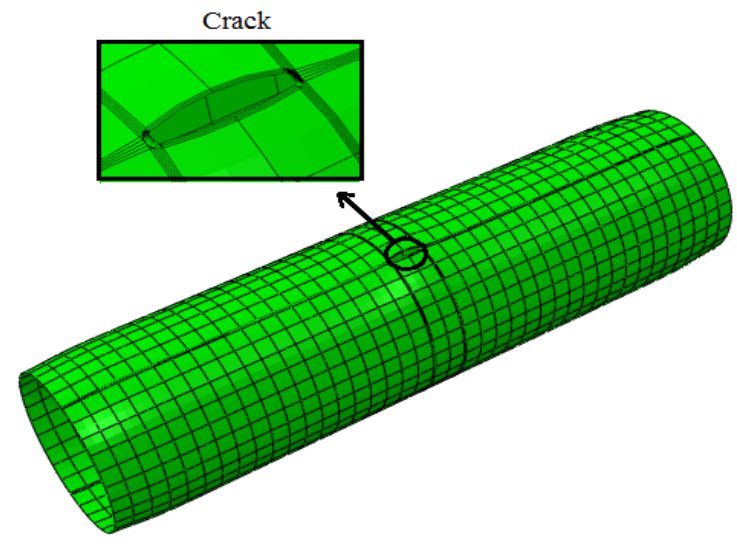

Figure 2: Meshing model of the cylinder.

\begin{tabular}{cccc}
\hline Models & Crack size (a) & Number of elements & Number of nodes \\
1 & $10 \mathrm{~mm}$ & 2508 & 30816 \\
2 & $20 \mathrm{~mm}$ & 3016 & 34217 \\
3 & $30 \mathrm{~mm}$ & 3604 & 39017 \\
4 & $40 \mathrm{~mm}$ & 4273 & 45212 \\
5 & $50 \mathrm{~mm}$ & 5022 & 52803 \\
6 & $60 \mathrm{~mm}$ & 5852 & 61789 \\
7 & $70 \mathrm{~mm}$ & 6762 & 72171 \\
8 & $80 \mathrm{~mm}$ & 7752 & 83949 \\
9 & $90 \mathrm{~mm}$ & 8823 & 97122 \\
10 & $100 \mathrm{~mm}$ & 9974 & 111690 \\
\hline
\end{tabular}

Table 2: The number of nodes and elements in the models studied for $\left(R_{\text {ext }}=500 \mathrm{~mm}, \mathrm{t}=20 \mathrm{~mm}=30 \mathrm{~mm}\right)$

\begin{tabular}{cccc}
\hline Models & External radius $\left(\mathrm{R}_{\text {ext }}\right)$ & Number of elements & Number of nodes \\
1 & $250 \mathrm{~mm}$ & 5168 & 15847 \\
2 & $300 \mathrm{~mm}$ & 6109 & 27351 \\
3 & $350 \mathrm{~mm}$ & 7060 & 42687 \\
4 & $400 \mathrm{~mm}$ & 8021 & 61855 \\
5 & $450 \mathrm{~mm}$ & 8992 & 84856 \\
6 & $500 \mathrm{~mm}$ & 9974 & 111690 \\
7 & $550 \mathrm{~mm}$ & 10965 & 142354 \\
8 & $600 \mathrm{~mm}$ & 11967 & 176852 \\
9 & $650 \mathrm{~mm}$ & 12979 & 215182 \\
10 & $700 \mathrm{~mm}$ & 14001 & 257344 \\
11 & $750 \mathrm{~mm}$ & 15033 & 303339 \\
\hline
\end{tabular}

Table 3: The number of nodes and elements in the models studied for $(\mathrm{a}=100 \mathrm{~mm}, \mathrm{t}=20 \mathrm{~mm}=30 \mathrm{~mm})$

- The boundary conditions of the models studied in the two positions are: $\mathrm{Ux}=\mathrm{Uy}=\mathrm{Uz}_{z}=\mathrm{U}_{\mathrm{Rx}}=\mathrm{U}_{\mathrm{Ry}}=\mathrm{U}_{\mathrm{Rz}}=0$ 


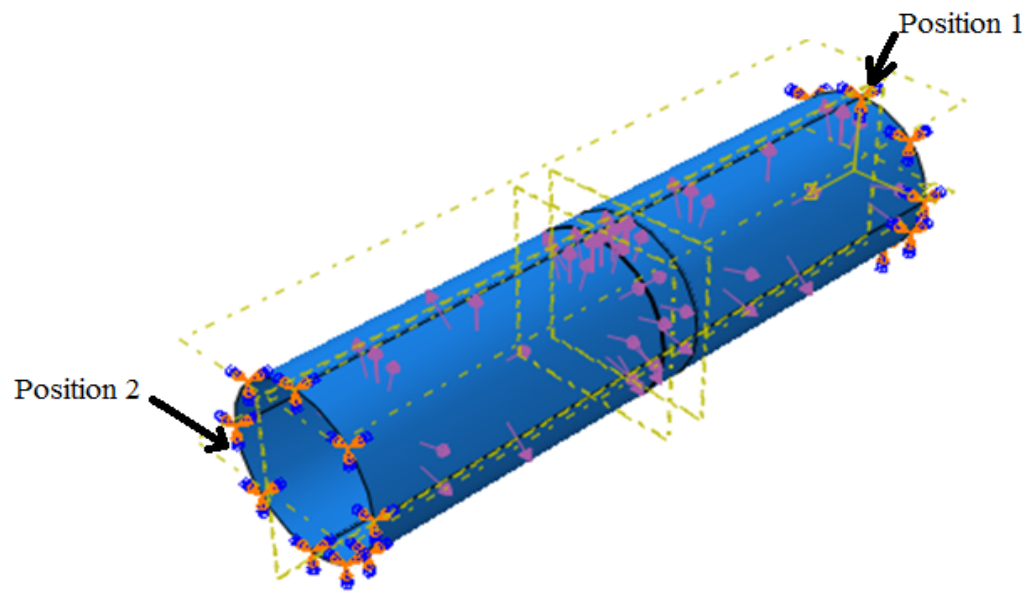

Figure 3: Boundary condition of the cylinder

\section{RESULTS AND DISCUSSION}

\section{Analysis of crack behavior}

7 o numerically simulate the fracture behaviour of pipes under high pressure using the finite element method, a crack of size "a" is initiated longitudinally in a pipeline of well-defined size by its radius " $\mathrm{R}$ " and thickness " $\mathrm{t}$ ". The cracked pipe is subjected to a pressure of 100 bar. Two approaches, elastic and elastic-plastic, were used in thisstudy.The results of this modelling are shown in Figs. 4 and 5. The analysis of these figures clearly shows that the Jintegral increases as the cracking defect advances. This increase is even more pronounced when the crack is initiated in a thin pipe (Fig. 4 a, b).

It should be noted, however, that compared to the elastic-plastic approach, the elastic model results in larger J-integral values (Fig. 4b). This difference is much more pronounced for long cracks. The elastic-plastic approach is more realistic as the material used for pipelines has a ductile behaviour, characterised by a very high resistance to cracking (toughness). It is clearly shown in Fig. 6a, b, that cracks initiated in a thick pipe are more stable than those initiated in a thin tubular structure. This behaviour is explained by the low values of the integral, regardless of the elastic or elastic-plastic approach used. This explicitly shows that thin pipes have a higher risk of bursting than thick pipes. This risk is strongly increased when the crack is initiated in a large diameter pipe (fig.5a, b). This figure shows that, irrespective of the elastic or elasticplastic approach used, cracks initiated in large pipes under high pressures are more unstable. This instability is much more pronounced for long cracking faults initiated in pipes exhibiting elastic-plastic behaviour. The relatively high values of the J-integral are characteristic of this instability. It is clearly established that the economic and efficient transport of hydrocarbons through pipelines requires an increase in pressure.

This behaviour shows that the damage of pipes under high pressure is closely related to their geometric characteristics: thickness-diameter. These two quantities are fundamental parameters for improving the efficiency and performance of hydrocarbon transport by pipeline. To this end, it would be relevant to analyse in more detail the effect of these geometric parameters on the cost-effectiveness of these tubular structures, subjected to high pressures. This analysis is carried out in terms of the variation of the elastic and elastic-plastic J-integral.

\section{Effect of geometric characteristics}

The profitability and performance of hydrocarbon transport by pipeline require increasingly high pressures. In order to meet this requirement, it is strictly necessary to play on both the geometric parameters of the tubular structure and especially on its diameter and thickness for a given type of pipe. To this end, it is relevant to analyze, numerically in three dimensions, the effect of these two geometric quantities on the mechanical behavior of pipes subjected to high pressures. Two approaches, elastic and elastic-plastic, were chosen for this study.The results are shown in Figs. 6 and 7. These two figures show the variation of the elastic and elastic-plastic J integral as a function of pipe thickness and radius respectively. It is explicitly shown in Fig. 6 that cracks initiated longitudinally in thick pipes, subjected to high pressures, are more stable regardless of the approach used. 

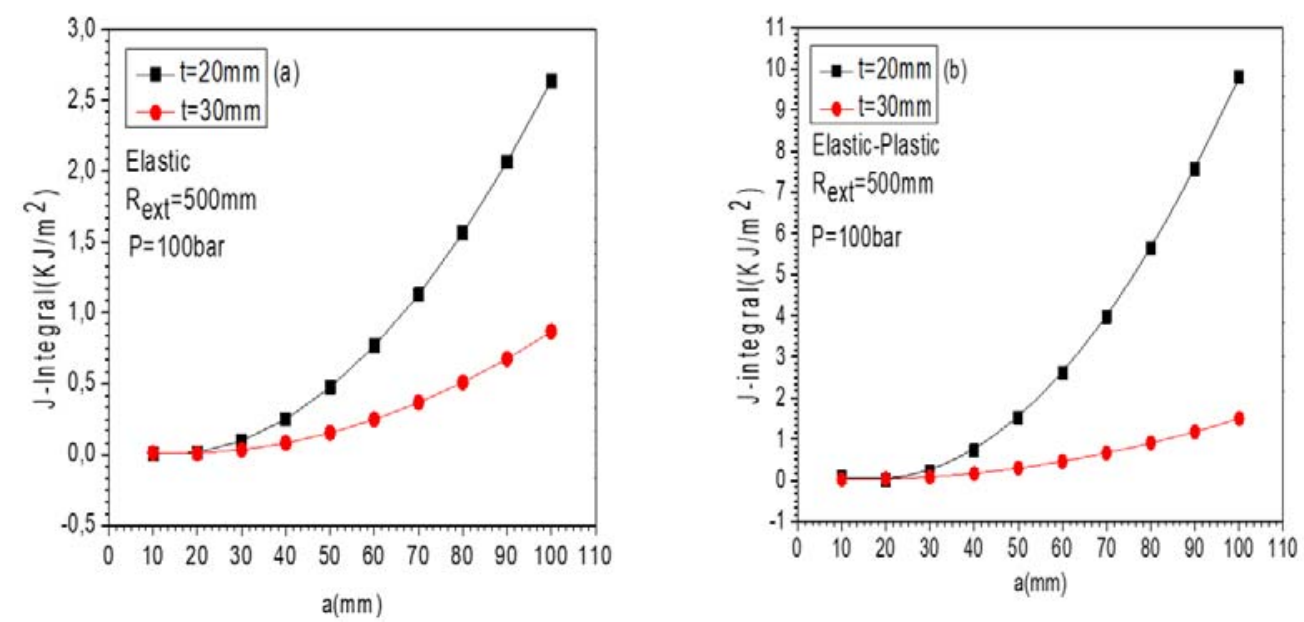

Figure 4: Variation of the J-integral according to the crack length for two different values of thickness ( $t$ ) of the pipe's elastic analyses, (b) elastic-plastic analyses.
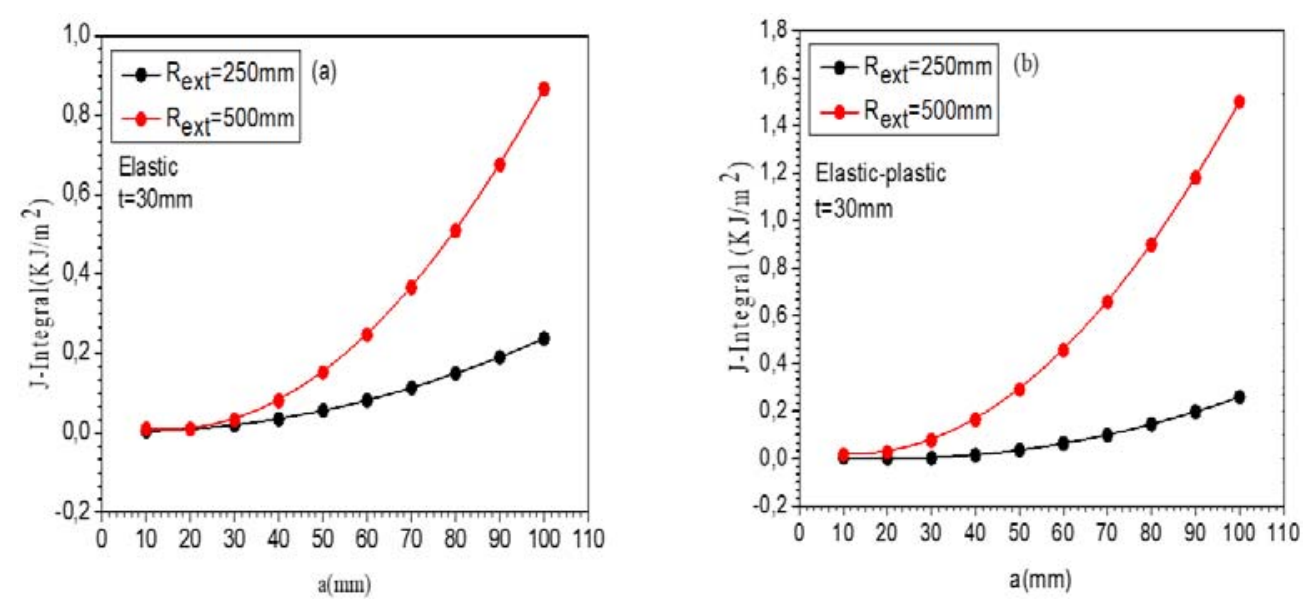

Figure 5: Variation of the J-integral according to the crack length for two different values of the external radius ( $\left.\mathrm{R}_{\text {ext }}\right)$ of the pipe's a) elastic analyses, b) elastic-plastic analyses

The results are shown in Figs. 6 and 7. These two figures show the variation of the elastic and elastic-plastic J-integral as a function of pipe thickness and radius respectively. It is explicitly shown in Fig. 6 that cracks initiated longitudinally in thick pipes, subjected to high pressures, are more stable regardless of the approach used.

This stability is defined by low values of the J-integral. Conversely, these same cracks are very unstable when initiated in thin pipes. The high values of this failure parameter are characteristic of the risk of propagation of such cracking defects. This cracking behavior clearly shows that thick pipes have a good resistance to bursting and ensure a good efficiency of this type of transport. It should be noted, however, that this geometric parameter is a key determinant of the rigidity of the tubular structure. These thick structures are more rigid and resistant to higher and higher pressures and present a more efficient means of transport. To make this type of transport even more efficient and to withstand high pressures, it is strongly recommended to use large diameter pipelines. These allow for increased flow rates and good resistance to high media pressures. The effect of this geometric parameter on the behavior of longitudinal cracks initiated in pipes is illustrated in Fig. 8. It should be noted, however, that large diameter pipes increase the risk of instability of these cracks by increasing the J-integral, regardless of the approach used. To reduce this risk, it is necessary to use large diameter pipes, as shown in Fig. 6. The latter clearly illustrates that cracks initiated in large diameter pipes are stable and pose no risk of propagation. These tubular structures have a high resistance to bursting as shown in Fig. 9a. Analysis of this figure indicates that the propagation of long longitudinal cracks, initiated in thicker diameter pipelines, is stable (Fig. 9b). 


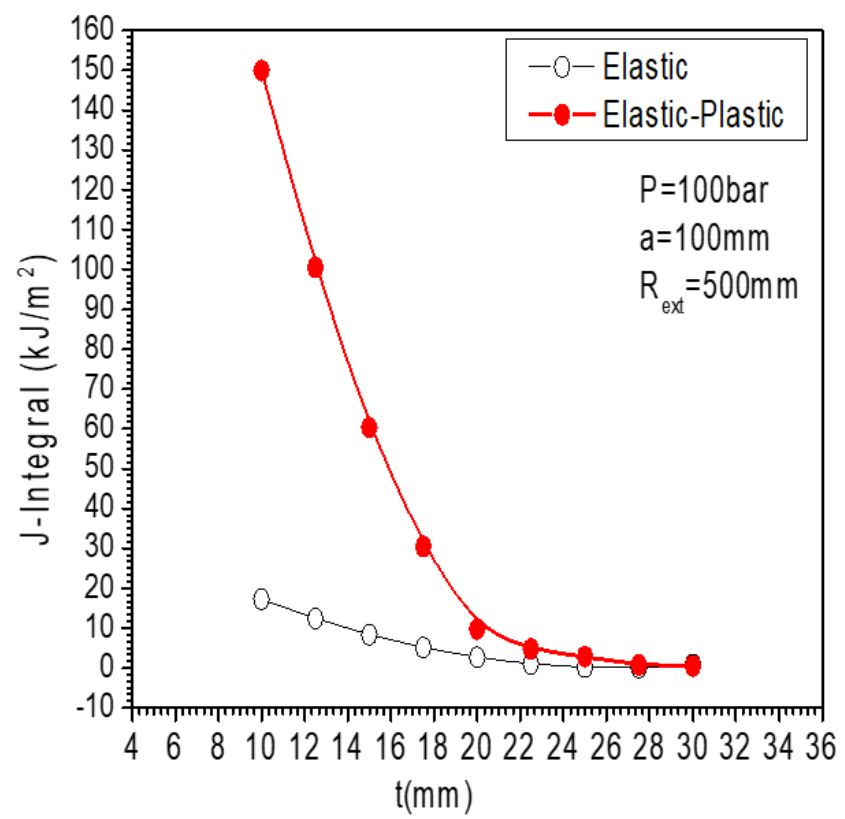

Figure 6: Variation of the J-integral according to the thickness ( $t$ ) for the elastic and elastic-plastic analyses of the pipes.

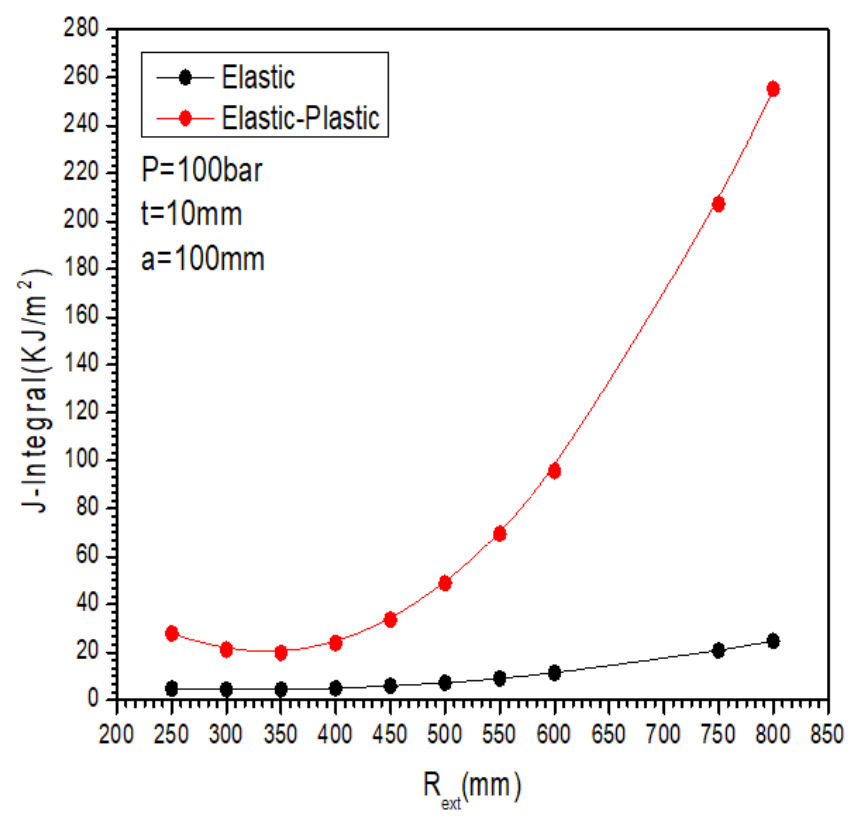

Figure 7: Variation of the J-integral according to the external radius (Rext) for the elastic and elastic-plastic analyses of the pipes.

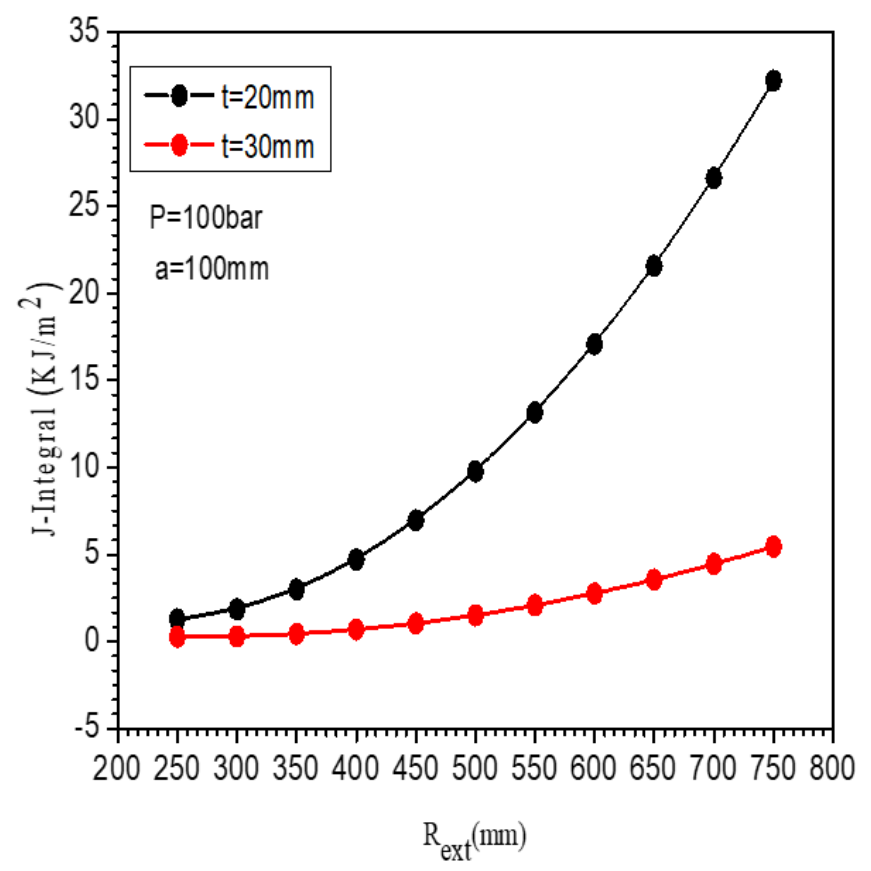

Figure 8: Variation of the J-integral according to the external radius $\left(\mathrm{R}_{\text {ext }}\right)$ for the two different values of thickness ( $\left.t\right)$ for elastic-plastic analyses of the pipes.

The results obtained in this work show that, in order to withstand the increasingly high pressures required to improve the performance of pipeline transport, these tubular structures must be large in diameter and thick. Thicknesses significantly reduce the risk of bursting of large diameter pipes (Fig. 10). The negative effect of the large pipe size (diameter) is compensated for by the increased thickness. 

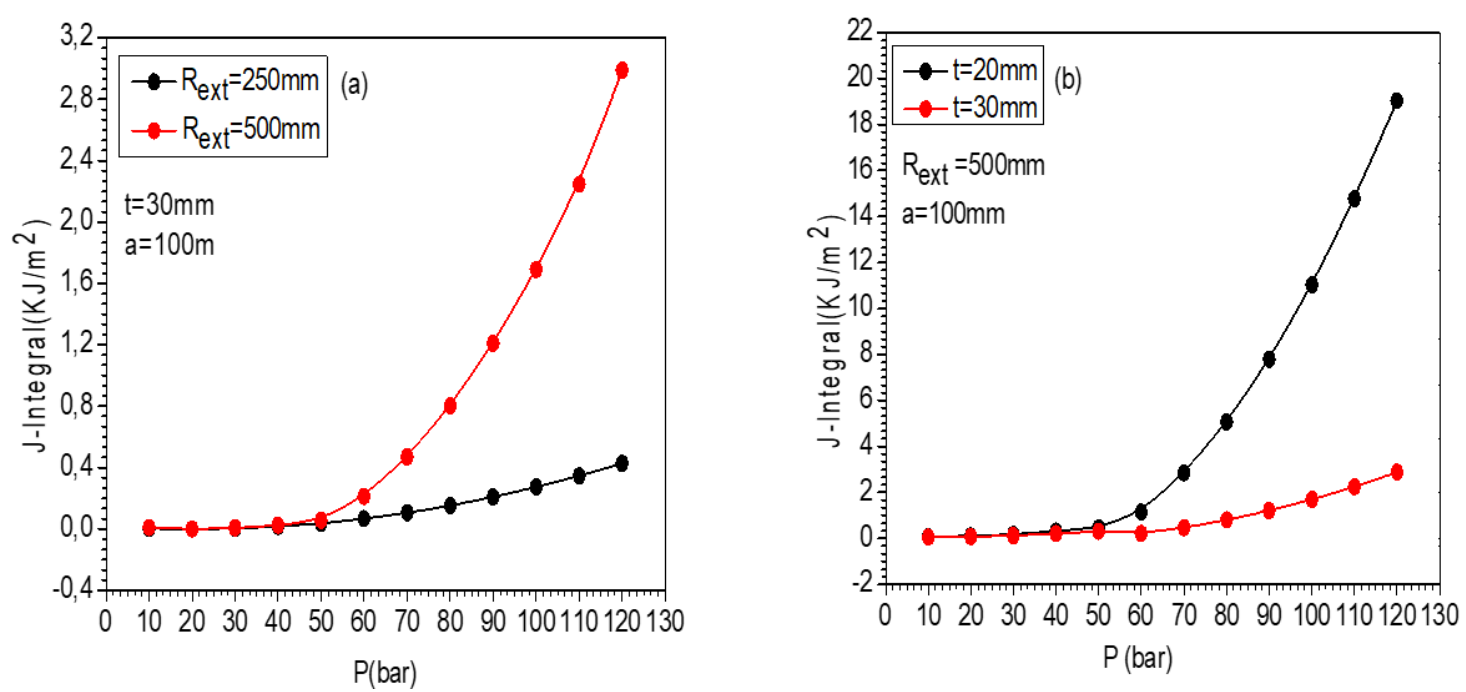

Figure 9: Variation of the J-integral according to the internal pressure (P) for the two different values of: (a) external radius ( $\left.\mathrm{R}_{\text {ext }}\right)$ and (b) thickness (t) for elastic-plastic analyses of the pipes.

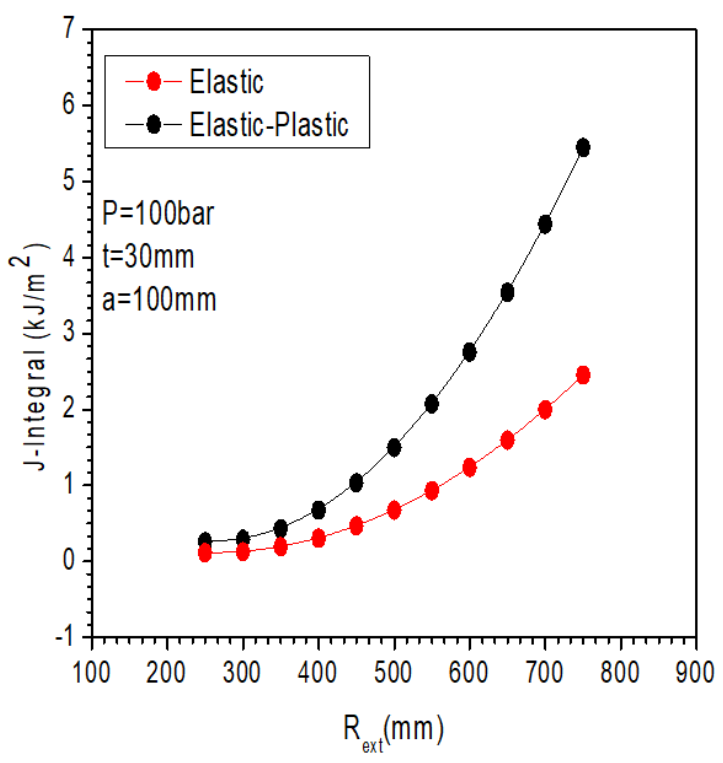

Figure 10: Variation of the J-integral according to the external radius $\left(\mathrm{R}_{\text {ext }}\right)$ for(a) the elastic and (b) elastic-plastic analyses of the pipes.

\section{Effect of location}

In order to highlight the location of the preferential site of initiation of the cracking defect, a comparative study of the behavior of a longitudinal and circumferential crack of size "a", initiated in a pipe under high pressure was carried out (fig.11).The analysis of this figure shows that, regardless of the elastic or elastic-plastic approach and the size of the crack, the risk of bursting is more likely in the longitudinal direction than in the circumferential direction. Compared to the elastic approach (Fig. 11 a), the elastic-plastic model results in a high probability of crack propagation. This risk of pipe damage is more pronounced for relatively long cracks (fig.11b). The values of the " J-integral " growth criterion help to explain this crack instability. This behavior shows that the ultimate pressures stress the pipes more strongly according to their length than according to their circumference. The results shown in this figure explicitly demonstrate that threedimensional numerical modelling, using the finite element method, can predict not only the damage of pipes under high pressure but also its preferential direction. In other words, long cracks, under the same loading conditions, propagate more easily along the pipes. In the case of short cracks "a<50mm", the effect of the nature of the crack (longitudinal and circumferential) is very small, the very small difference between the J-integrals for these two types of cracks is characteristic of this behavior. Beyond this size and whatever the elastic or elastic-plastic approach, this deviation 
increases with the progress of the crack. In the elastic approach and whatever the advance of the cracking defect, these two types of cracks are more stable, the low values of the J integral compared to that resulting from the elastic-plastic behavior allow to explain this stability.
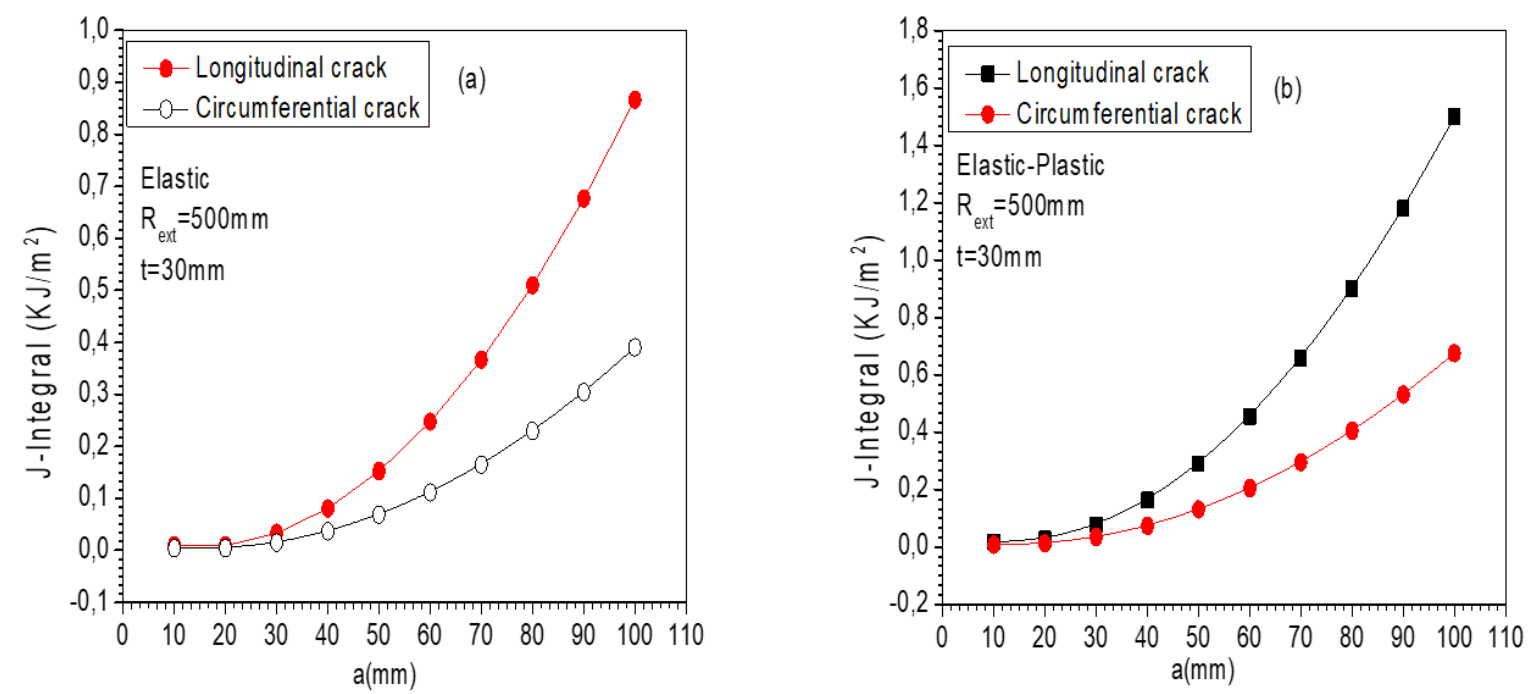

Figure 11: Variation of the J-integral as a function of crack size for longitudinal and circumferential cracks initiated in a pipeline in (a) elastic and (b)elastic plastic analyses.

\section{Probabilistic Elastic-Plastic Fracture Mechanic Analysis}

\section{Random parameters and fracture response}

7 he probabilistic approach involves the probability assessment of the damage of structure. This approach allows analyzing the chain of events and equipment failures and estimating the total probability of this problem. Main disadvantage of this approach is related to the lack of statistics on equipment failure [21-23]. Probabilistic calculations for ductile materials have mainly been contributed in the past decade by Mechab et al [24].In this part a probabilistic fracture mechanics model established from three-dimensional FEM analyses of axial cracked pipes subjected to internal pressure. The FEM results were used to develop statistical parameters that were used with the deterministic model in a Monte Carlo analysis.

The density function is evaluated by using Monte Carlo method. The basic idea is to draw random samples for the input parameters, then to compute the mechanical response for eachsample. we have realised this work by the FORTRAN program, response by using Monte Carlo method. To achieve a highaccuracy of the results, we have carried out $10^{5}$ simulations. The random components are: material tensile parameters, $\mathrm{E}, \mathrm{v}, \alpha, \mathrm{n}$ and applied stress $\sigma_{\mathrm{ap}}$, geometric parameters.

The crack length (a)ranged from $10 \mathrm{~mm}$ to $100 \mathrm{~mm}$, and the external radius $\left(\mathrm{R}_{\text {ext }}\right)$ varied from $250 \mathrm{~mm}$ to $750 \mathrm{~mm}$ and the thickness (t). All or some of these variables can be modelled as random variables. Hence, any relevant fracture response, such as the J integral, should be evaluated by the probability.

The safety margin $(J)(x i)$ is the probabilistic design rule, which defines the plate safety by the condition $(J)\left(x_{i}\right)>0$ and the plate failure by $(J)\left(x_{i}\right) \leq 0$. In the Fig. 12 the probability density function is obtained by fitting the histogram with theoretical models are investigated: the Gaussian law offers an acceptable approximation of the J probability density function, with good estimation of the average.

Fig. 13 and 14 shows the cumulative probability of $\mathrm{J}$ integral for different values of the crack size and of the external radius $\left(R_{\text {ext }}\right)$. We noted that when the crack size and the external radius $\left(R_{\text {ext }}\right)$ is length the value of the cumulative probability of $\mathrm{J}$ is large. It can be seen that the margin increases significantly with the uncertainties related to the crack size and of the mean pipe's radius to its thickness $(\mathrm{Rm} / \mathrm{t}$ ), leading to larger failure probability. The uncertainty in the crack size (a) and the external radius $\left(\mathrm{R}_{\text {ext }}\right)$, have a significant effect on increasing the probability of failure of piping. Finally, the failure probabilities depend on the crack size and geometries of piping. 


\begin{tabular}{ccc}
\hline Variable & Mean & Coefficient of variation (COV) \\
Young modulus (E) & $203 \mathrm{MPa}$ & $1 \%$ \\
Ramberg-osgood exponent $(\mathrm{n})$ & 3.887 & $1 \%$ \\
Ramberg-osgood coefficient $(\alpha)$ & 18.826 & $1 \%$ \\
Crack length (a) & $10 \mathrm{~mm}$ & $2 \%$ \\
Thickness (t) & $30 \mathrm{~mm}$ & $1 \%$ \\
External radius(Rext) & $500 \mathrm{~mm}$ & $2 \%$ \\
Internal pressure $(\mathrm{P})$ & $100 \mathrm{bar}$ & $1 \%$ \\
\hline
\end{tabular}

Table 4: Random variables and corresponding parameters.

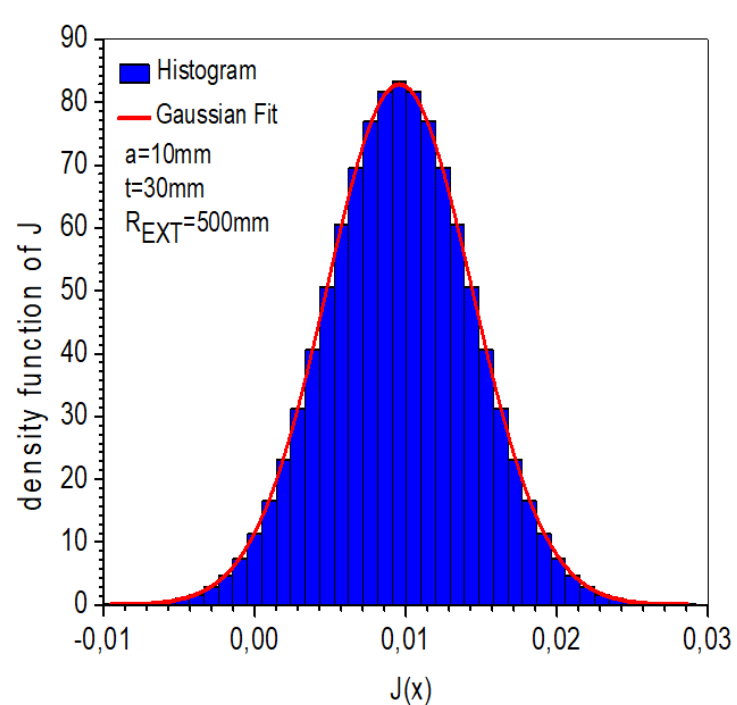

Figure 12: Histogram and probability density function of $\mathrm{J}$ integral.

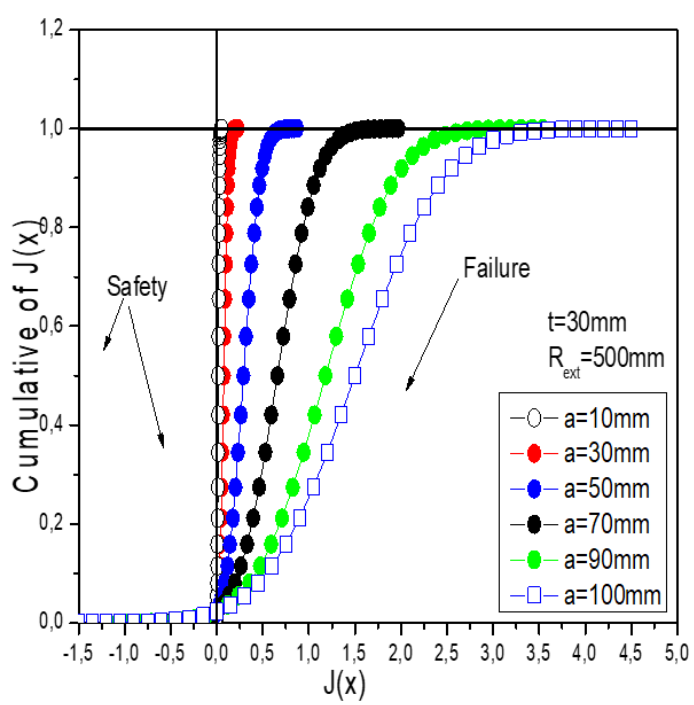

Figure 13: The cumulative of $\mathrm{J}$ integral for different values of crack seize (a).

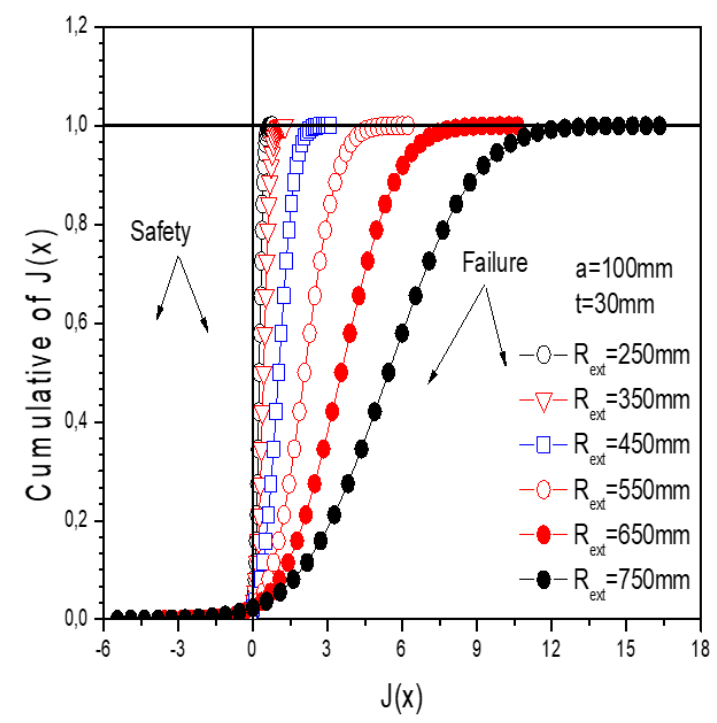

Figure 14: The cumulative of $\mathrm{J}$ integral for different values of the external radius (Rext). 


\section{CONCLUSION}

$\mathrm{T}$ he piping system is an important element in power plants, and thus application of fracture mechanicsanalysis to such pressurised piping is important in structural integrity assessment of plant components. The fracture mechanics is to describe the correlation between standard specimen fracture and macroscopic fracture of the cracked structure, through the use of various crack-tip governing parameters. The objective of this study was to evaluate of the ductile damage of the cracked pipe for J-estimation models used in probabilistic elastic plastic fracture mechanics subjected to internal pressure load. It is based on the engineering J estimation for the ductile fracture mechanics analyses using the three-dimensional finite element calculations of the J-integral. The effect of the external radius $\left(\mathrm{R}_{\text {ext }}\right)$, thickness of the pipe (t), length crack (a), applied loads (P) and crack position has studied. The FEM results were used to develop statistical parameters that were used with the deterministic model in a Monte Carlo analysis. We note that the crack size and the external radius $\left(\mathrm{R}_{\mathrm{ext}}\right)$ of the pipes are an important factor influencing on the durability of piping.

\section{REFERENCES}

[1] Budhe, S., Banea, M.D. de Barros, S. (2020). Prediction of the burst pressure for defective pipelines using different semi-empirical models, Frattura ed Integrità Strutturale, 52, pp. 137-147; DOI: 10.3221/IGF-ESIS.52.12.

[2] Nikhil, R., Krishnan, S.A., Sasikala, G., Moitra, A., Shaju, K., Albert., Bhaduri Study, A.K.,(2021). On fracture transferability from compact type specimen to pipe for 316LN stainless steel”, Int. J. Pres. Ves. Pip. 192, 104437. DOI: 10.1016/j.ijpvp.2021.104437

[3] Barsouma, I., Yurindatama, D T. (2020). Collapse analysis of a large plastic pipe using cohesive zone modelling technique, Int. J. Pres. Ves. Pip. 187, 104155. DOI: 10.1016/j.ijpvp.2020.104155.

[4] Zheng, Q., Abdelmoety, A K., Li, Y., Kainat, M., Nader ,Y G., Adeeb, S.,(2021). Reliability analysis of intact and defected pipes for internal pressure related limit states specified in CSA Z622:19”, Int. J. Pres. Ves. Pip. 192, 104411. DOI: https ://doi.org/10.1016/j.ijpvp.2021.104411

[5] Chattopadhyay, J., Dutta, B.K., Vaze, K.K.,(2014). Development of new correlations for improved integrity assessment of pipes and pipe bends", Nucl .Eng. Des, 269, pp. 108-115. DOI: 10.1016/j.nucengdes.2013.08.015

[6] R6 (2001). Assessment of the Integrity of Structures Containing Defects, Revision 4. British Energy Generation Ltd, Gloucester.

[7] Weltevreden, M., Hadley,I., Coules, H.,(2021). Probabilistic treatment of pipe girth weld residual stress in fracture assessment, Int. J. Pres. Ves. Pip. 192, 104397. DOI: 10.1016/j.ijpvp.2021.104397

[8] Muthanna, B.G.N., Bouledroua, O., Benziane M.M., Setvati, M R, Djukic, M B., (2020). Assessment of corroded

[9] API 5L X52 pipe elbow using a modified failure assessment diagram, Int. J. Pres. Ves. Pip. 190, 104291. DOI: $10.1016 /$ j.ijpvp.2020.104291

[10] Salem, B., Mechab, B., Berrahou, M., BachirBouiadjra, B., Serier, B. (2019). Failure Analyses of Propagation of Cracks in Repaired Pipe Under Internal Pressure, Journal of Failure Analysis and Prevention. 19(1), pp. 212-218. DOI:10.1007/s11668-019-00592-3

[11] Mechab, B., Serier, B., Bachir Bouiadjra, B., Kaddouri, K., Feaugas, X. (2011). Linear and non-linear analyses for semi-elliptical surface cracks in pipes under bending, Int. J. Pres. Ves. Pip. 88, pp. 57-63.

DOI: 10.1016/j.ijpvp.2010.11.001

[12] Mechab, B., Medjahdi, M., Salem, M., Serier, B. (2020). Probabilistic elastic-plastic fracture mechanics analysis of propagation of cracks in pipes under internal pressure, Frattura ed Integrità Strutturale, 54, pp. 202-210. DOI: $110.3221 /$ IGF-ESIS.54.15.

[13]Jeong, S-H., Won, M-G., Huh, N-S., Choi, J-B., Kim, W-G., Lee, H-Y. (2021). On elastic-plastic and creep fracture mechanics parameters estimates of non-idealized axial through-wall crack in pressurized pipe, Int. J. Pres. Ves. Pip. 189, 104292. DOI: 10.1016/j.ijpvp.2020.104292.

[14] Bassindale, C., Wang, X., Tyson., William, R., Xu, S., (2020). Fast ductile fracture: Effect of inertia on propagation resistance and CTOA in pipe steels, Int. J. Pres. Ves. Pip. 187, 104163. DOI: 10.1016/j.ijpvp.2020.104163.

[15] Bianchetti, C.,Pino Muñoz, D., Leblé, B., Bouchard, P-O. (2021). Ductile failure prediction of pipe-ring notched AISI316L using uncoupled ductile failure criteria, Int. J. Pres.Ves.Pip.191, 104333. DOI: 10.1016/.ijpvp.2021.104333

[16] Qian, G., Niffenegger, M.,Karanki, D.R., Li, S. (2013). Probabilistic leak before-break analysis with correlated input parameters, Nucl. Eng. Des. 254, pp. 266-271 DOI: 10.1016/S0308-0161(96)00034-8. 
[17] Tee, K.F., Khan, L.R., Chen, H.P. (2013). Probabilistic failure analysis of underground flexible pipes, Struct. Eng. Mech. 47(2), pp. 167-183. DOI: 10.12989/sem.2013.47.2.167.

[18] Rahman, S. (1995). A stochastic model for elastic-plastic fracture analysis of circumferential through-wall-cracked pipes subject to bending, Eng. Fract. Mech. 52, pp. 265-288. DOI: 10.1016/0013-7944(95)00018-Q.

[19] Rahman, S. (2000). Probabilistic elastic-plastic fracture analysis of circumferentially cracked pipes with finite-length surface flaws, Nucl. Eng. Des. 195, pp. 239-260. DOI: 10.1016/S0029-5493(99)00214-9.

[20] ABAQUS (1998), ABAQUS Standard/User's Manual, Version 5.8-1. HibbitKarlsson\& Sorensen, Inc., Pawtucket, RI, USA.

[21] Saxena, S., Ramachandra Murthy, D S. (2004). Elastic-plastic fracture mechanics based prediction of crack initiation load in through-wall cracked pipes, Engineering Structures 26, pp. 1165-1172. DOI: $10.1016 /$ j.engstruct.2004.02.002

[22] Rahman, S. (1997). Probabilistic fracture analysis of pipes with circumferential flaws, Int. J. Pres. Ves. Pip. 70, pp. 223-236. DOI: 10.1016/S0308-0161(96)00034-8.

[23] Rahman, S., Brust, F.W. (1997). Approximate methods for predicting J-integral of a circumferentially surface-cracked pipe subject to bending, Int. J. Fract. 85, pp. 11-130. DOI: 10.1023/A:1007322018722

[24] Yusa, N., Song, H., Iwata, D.,Uchimoto, T., Takagi, T., Moroic, M., (2021). Probabilistic evaluation of EMAR signals to evaluate pipe wall thickness and its application to pipe wall thinning management", NDT \& E International 122 , 10247. DOI: $10.1016 /$ j.ndteint.2021.102475

[25] Mechab, B., Chioukh, N., Mechab Boubaker, B., Serier, B. (2018). Probabilistic Fracture Mechanics for Analysis of Longitudinal Cracks in Pipes Under Internal Pressure, Journal of Failure Analysis and Prevention. 18(6), pp. 16431651. DOI: $10.1007 /$ s11668-018-0564-8. 